\title{
Specific insulin and proinsulin secretion in glucokinase-deficient individuals
}

V.C. Pardini ${ }^{1}$, G. Velho ${ }^{2}$, R. Reis ${ }^{1}$, S. Purisch ${ }^{1}$, H. Blanché ${ }^{3}$, J.G.H. Vieira ${ }^{4}$ and R.C.S. Moisés ${ }^{4}$

\author{
${ }^{1}$ Centro de Pesquisas da Endocrinologia, Hospital Santa Casa, \\ Belo Horizonte, MG, Brasil \\ ${ }^{2}$ INSERM U 358, Hôpital Saint-Louis, and ${ }^{3}$ Fondation Jean Dausset, \\ CEPH, Paris, France \\ ${ }^{4}$ Disciplina de Endocrinologia, Universidade Federal de São Paulo, \\ São Paulo, SP, Brasil
}

\section{Correspondence \\ V.C. Pardini \\ Instituto de Patologia Clínica \\ H. Pardini \\ Rua Aimorés, 33 \\ 30140-070 Belo Horizonte, MG \\ Brasil \\ Fax: + 55-31-225-1272 \\ E-mail: vpardini@ labhpardini.com.br}

Publication supported by FAPESP.

Received August 4, 1998

Accepted January 26, 1999

\section{Abstract}

Glucokinase (GCK) is an enzyme that regulates insulin secretion, keeping glucose levels within a narrow range. Mutations in the glucokinase gene cause a rare form of diabetes called maturity-onset diabetes of the young (MODY). An early onset (less than 25 years), autosomal dominant inheritance and low insulin secretion stimulated by glucose characterize MODY patients. Specific insulin and proinsulin were measured in serum by immunofluorimetric assays (IFMA) during a 75-g oral glucose tolerance test (OGTT). Two kindreds (SA and LZ) were studied and compared to non-diabetic unrelated individuals (control group 1) matched for age and body mass index (BMI). In one kindred, some of these subjects were also obese (BMI $>26 \mathrm{~kg}$ / $\mathrm{m}^{2}$ ), and other family members also presented with obesity and/or lateonset NIDDM. The MODY patients were also compared to a group of five of their first-degree relatives with obesity and/or late-onset NIDDM. The proinsulin profile was different in members of the two MODY kindreds. Fasting proinsulin and the proinsulin/insulin ratio were similar in MODY members of kindred LZ and subjects from control group 1, but were significantly lower than in MODY members of kindred $\mathrm{SA}(\mathrm{P}<0.02$ and $\mathrm{P}<0.01$, for proinsulin and proinsulin/insulin ratio, respectively). Moreover, MODY members of family SA had higher levels of proinsulin and proinsulin/insulin ratio, although not significantly different, when compared to their first-degree relatives and to subjects from control group 2. In conclusion, we observed variable degrees of proinsulin levels and proinsulin/insulin ratio in MODY members of two different kindreds. The higher values of these parameters found in MODY and non-MODY members of kindred SA is probably related to the obesity and late-onset NIDDM background present in this family.
Key words

- Proinsulin

- Insulin

- MODY

- Glucokinase

- Obesity 


\section{Introduction}

Maturity-onset diabetes of the young (MODY) is a genetically heterogeneous syndrome that can be caused by heterozygous mutations in the glucokinase (GCK) gene in approximately $50 \%$ of MODY cases in France (1). This form is characterized by an early onset ( $<25$ years old) of diabetes mellitus, mild hyperglycemia and autosomal dominant inheritance (1). Mutations in the GCK gene cause impaired insulin secretion in response to glucose (2), a reduction in postprandial hepatic glycogen synthesis and an increased rate of gluconeogenesis after meals (3).

Proinsulin, the precursor of insulin, is biologically less active than insulin and an increased secretion of these molecules is considered to reflect $\beta$-cell dysfunction $(4,5)$. A disproportionate increase of proinsulin and its conversion intermediates, and an increasing proinsulin-to-insulin ratio are associated with insulin resistance syndrome $(6,7)$. Patients with increased insulin secretion without hyperglycemia, such as obesity, present hyperproinsulinemia without an increase in the proinsulin-to-insulin ratio (7). Proinsulin levels have not been extensively studied in glucokinase-deficient subjects. We report here the assessment of specific insulin and proinsulin in members of two Brazilian glucokinase-deficient MODY families.

\section{Material and Methods}

\section{Individuals}

We studied two MODY families (LZ and SA) with different mutations in the GCK gene. In the LZ kindred the E248X mutation was found in the proband and three of his sons with MODY (8). These patients were compared to six non-diabetic unrelated individuals (control group 1) matched for age and body mass index (BMI). In the SA kindred the V401del1 mutation was detected in
6 subjects with MODY (8). Some of these subjects were also obese (BMI $>26 \mathrm{~kg} / \mathrm{m}^{2}$ ), and other family members also presented with obesity and/or late-onset non-insulindependent diabetes (NIDDM). The MODY patients were compared to a group of five of their first-degree relatives with obesity and/ or late-onset NIDDM, and to eleven nondiabetic unrelated individuals (control group 2) matched by age and BMI.

The patients' blood glucose was controlled only by diet and they were not using any drug. Normal glucose tolerance (NGT), impaired fasting glucose (IGT) and diabetes mellitus (DM) were defined according to the new diagnosis and classification of diabetes mellitus by the Expert Committee Report (9). The control group consisted of outpatients seen at the Endocrinology Division of the Universidade Federal de São Paulo who showed NGT after the oral glucose tolerance test (OGTT). All individuals and patients gave informed consent to take part in the study. The study was approved by the University Ethics committee.

\section{Analytical methods}

All individuals underwent an OGTT after a 10-h fast and blood samples were collected at 0, 30, 60 and 120 min after $75 \mathrm{~g}$ glucose ingestion for plasma glucose, serum insulin and proinsulin measurement. Glucose was assayed by the glucose oxidase method. Serum insulin and proinsulin were measured by an immunofluorimetric assay. These assays detect 100\% human insulin and proinsulin, respectively, and both show $100 \%$ cross-reactivity with 64,65 proinsulin and split 65,66 proinsulin and no cross-reactivity with des 31,32 proinsulin or split 32,33 proinsulin. Beta-cell function in response to the oral ingestion of $75 \mathrm{~g}$ glucose was quantified as the ratio of the incremental plasma insulin response (RIR) above basal levels at 30 min to that of plasma glucose, divided by basal plasma insulin levels ([ $\Delta 30-0-$ min in- 
sulin/ $\Delta 30-0$-min glucose]/basal insulin) (10).

\section{Statistical analysis}

Data are reported as mean $\pm \mathrm{SD}$, unless otherwise stated. Non-parametric tests were performed. The Mann-Whitney $U$ and the Kruskal-Wallis tests were used when comparing two or three groups, respectively. Quantitative traits were compared by analysis of variance (ANOVA). When ANOVA was significant, comparisons between pairs were made by the Tukey-Kramer HSD test (11). Data were analyzed using the Statistical Package for Social Science for Windows, version 7.0 (SPSS Inc., Chicago, IL). A P value less than 0.05 was considered statistically significant.

\section{Results}

The clinical and metabolic profiles of family members and control groups are shown in Table 1 . The relative insulin response (RIR) was significantly decreased in MODY members of kindred LZ as compared to control group 1, as expected (2).
RIR was significantly decreased both in MODY members and in the first-degree relatives of kindred SA compared to control group 2. The proinsulin profile was different in members of the two MODY kindreds. Fasting proinsulin and the proinsulin/insulin ratio were similar in MODY members of kindred LZ and subjects from control group 1 , but were significantly lower when compared to those of MODY members of kindred SA $(\mathrm{P}<0.02$ and $\mathrm{P}<0.01$ for proinsulin and proinsulin/insulin ratio, respectively). Moreover, MODY members of family SA had higher levels of proinsulin and a higher proinsulin/insulin ratio, although not significantly different, when compared to their first-degree relatives and to subjects from control group 2.

Stepwise multiple regression analysis was performed with proinsulin or the proinsulin/ insulin ratio as the dependent variable and sex, age, BMI, glucokinase mutation status, fasting and 2-h glucose, fasting insulin and RIR as independent variables. Data were log-transformed and all subjects were included in the analysis. The BMI and RIR (inverse correlation) accounted for 53\%

Table 1 - Clinical and metabolic profiles of family members.

Data are reported as mean and interquartile range. The Kruskal-Wallis (rank sums) and Tukey-Kramer HSD tests with log-transformed data were used when the results of the Kruskal-Wallis test were significant $(\mathrm{P}<0.05)$. $\# \mathrm{P}<0.05$ compared to control group 2 , and $* \mathrm{P}<0.05$ compared to unaffected relatives. a $[\Delta 30-0-$ min insulin/ $\Delta 30-0$-min glucose $] /$ basal insulin. W, Women; $M$, men.

\begin{tabular}{|c|c|c|c|c|c|c|c|}
\hline & $\begin{array}{c}\text { Kindred LZ } \\
\text { (MODY subjects) }\end{array}$ & Control group 1 & $P$ & $\begin{array}{c}\text { Kindred SA } \\
\text { (MODY subjects) }\end{array}$ & Control group 2 & $\begin{array}{l}\text { First-degree } \\
\text { relatives }\end{array}$ & $P$ \\
\hline Subjects/sex (N) & $4(0 \mathrm{~W} / 4 \mathrm{M})$ & $6(3 \mathrm{~W} / 3 \mathrm{M})$ & - & $6(3$ W/3 M) & 11 (5 W/6 M) & $5(3 \mathrm{~W} / 2 \mathrm{M})$ & - \\
\hline Age (years) & $21(10-37)$ & $27(25-30)$ & 0.24 & $21(16-26)^{*}$ & $26(23-31)$ & $37(29-47)$ & $<0.02$ \\
\hline BMI $\left(\mathrm{kg} / \mathrm{m}^{2}\right)$ & $19.8(16.4-23.5)$ & $22.0(18.0-24.3)$ & 0.34 & $26.5(24.0-30.4)$ & $27.8(24.0-30.0)$ & $27.9(23.7-32.6)$ & 0.97 \\
\hline Fasting glucose (mmol/l) & $6.3(5.4-6.7)$ & $4.7(3.4-5.3)$ & $<0.02$ & $6.8(6.5-7.3)^{\# *}$ & $5.1(4.7-5.2)$ & $4.8(4.2-5.4)$ & $<0.003$ \\
\hline Fasting insulin (pmol/l) & $18(12-22)$ & $39(15-62)$ & 0.20 & $39(15-68)$ & $35(15-41)$ & $47(28-65)$ & 0.45 \\
\hline Fasting proinsulin (pmol/l) & $0.23(0.10-0.48)$ & $0.63(0.10-1.20)$ & 0.40 & $5.10(2.45-7.78)$ & $2.65(0.4-4.2)$ & $5.22(1.55-9.85)$ & 0.19 \\
\hline Fasting proinsulin/insulin (\%) & $1.6(0.5-3.8)$ & $1.1(0.6-1.8)$ & 0.59 & $17.7(5.6-28.7)$ & $9.5(2.7-12.7)$ & $10.5(4.1-18.8)$ & 0.43 \\
\hline 2-h glucose $(\mathrm{mmol} / \mathrm{l})$ & $10.3(8.0-13.7)$ & $4.4(3.1-5.2)$ & $<0.02$ & $9.8(7.3-13.1)^{\#}$ & $5.5(4.5-6.7)$ & $7.7(5.6-10.7)$ & $<0.04$ \\
\hline 2-h insulin (pmol/l) & $35(8-69)$ & $180(64-297)$ & $<0.03$ & $174(91-252)$ & $161(36-180)$ & $155(50-285)$ & 0.61 \\
\hline 2-h proinsulin (pmol/l) & $9.2(3.8-14.7)$ & $12.5(6.4-19.7)$ & 0.46 & $30.1(22.4-36.5)$ & $19.3(6.5-35.5)$ & $22.7(16.0-29.4)$ & 0.22 \\
\hline $\begin{array}{l}\text { Relative insulin response } \\
(1 / \mathrm{mmol})^{\mathrm{a}}\end{array}$ & $0.71(0.12-1.60)$ & $3.61(1.70-4.76)$ & $<0.04$ & $1.04(0.10-1.58)^{\#}$ & $3.28(1.10-5.17)$ & $0.60(0.26-1.00)^{\#}$ & $<0.04$ \\
\hline
\end{tabular}


$(\mathrm{P}<0.0001)$ and $8 \%(\mathrm{P}<0.02)$ proinsulin variance, respectively. Moreover, BMI, fasting insulin (inverse correlation), the presence of a glucokinase mutation, and the sex (women) accounted for $24 \%(\mathrm{P}<0.0002), 13 \%$ $(\mathrm{P}<0.004), 8 \%(\mathrm{P}<0.04)$ and $7 \%(\mathrm{P}<0.05)$, respectively, of the variance of proinsulin/ insulin ratio in these subjects.

\section{Discussion}

Many reports have shown that GCK-deficient patients have a reduced early insulin response after a glucose load $(1,4,12)$. In the present study we found abnormal ß-cell function in GCK-deficient individuals, even in the family with NIDDM patients (pedigree SA). In this family the proinsulin levels were increased maybe as a consequence of the stimulation of $\beta$-cells to release immature granules (5). An increased proinsulin/insulin ratio can be observed in individuals with an NIDDM background (6). Patients from pedigree SA showed a trend towards high values for this ratio maybe as a consequence of their NIDDM background.

We found here a failure of insulin release after a glucose stimulus in GCK-deficient individuals. GCK-deficient individuals showed normal levels of proinsulin but when obesity was also present, $\beta$-cells secreted more proinsulin. The proinsulin levels were increased in obese patients in spite of the low activity of the GCK enzyme. These results are in agreement with those of Hattersley and co-workers (13), showing normal proinsulin levels and proinsulin/insulin ratio in lean MODY subjects.

In conclusion, we observed variable degrees of proinsulin levels and proinsulin/ insulin ratio in MODY members of two different kindreds. The higher values of these parameters found in MODY and non-MODY members of kindred SA are probably related to the obesity and late-onset NIDDM background present in this family. The BMI was the most important independent determinant of high proinsulin levels and proinsulin/insulin ratio in these subjects.

\section{References}

1. Froguel P, Zouali H, Vionnet N, Velho G, Vaxillaire $M$, Sun $F$, Lesage $S$, Stoffel $M$, TakedaJ \& Passa P (1993). Familial hyperglycemia due to mutations in glucokinase: definition of a subtype of diabetes mellitus. New England J ournal of Medicine, 328: 697-702.

2. Velho G, Froguel $P$, Clement $K$, Pueyo ME, Rakotoambinina $B$, Zouali $H$, Passa $P$, Cohen D \& Robert J J (1992). Primary pancreatic beta-cell secretory defect caused by mutations in glucokinase gene in kindreds of maturity onset diabetes of the young. Lancet, 340: 444-448.

3. Velho G, Petersen KF, Perseghin G, Hwang JH, Rothman DL, Pueyo ME, Cline GW, Froguel P \& Shulman GI (1996). Impaired hepatic glycogen synthesis in glucokinasedeficient (MODY-2) subjects. J oumal of Clinical Investigation, 98: 1755-1761.

4. Galloway JA, Hooper SA, Spradlin CT, Howey DC, Frank BH, Bowsher RR \& Anderson J H (1992). Biosynthetic human proinsulin. Review of chemistry, in vitro and in vivo receptor binding, animal and human pharmacology studies, and clinical trial ex- perience. Diabetes Care, 15: 666-692.

5. Yoshioka N, Kuzuya T, Matsuda A, Taniguchi M \& Iwamoto Y (1988). Serum proinsulin levels at fasting and after oral glucose load in patients with type 2 (noninsulin-dependent) diabetes mellitus. Diabetologia, 31: 355-360.

6. Haffner SM, Mykkänen L, Valdez RA, Stern MP, Holloway DL, Monterrosa A \& Bowsher RR (1994). Disproportionately increased proinsulin levels are associated with the insulin resistance syndrome. J ournal of Clinical Endocrinology and Metabolism, 79: 1806-1810.

7. Leahy J L (1996). Impaired ß-cell function with chronic hyperglycemia: "overworked ß-cell" hypothesis. Diabetes Reviews, 4: 298-319.

8. Velho $\mathrm{G}$, Blanché $\mathrm{H}$, Vaxillaire $\mathrm{M}$, BellanneChantelot C, Pardini VC, Timsit J , Passa P, Deschamps I, Robert JJ, Weber IT, Marotta D, Pilkis SJ , Lipkind GM, Bell GI \& Froguel P (1997). Identification of 14 new glucokinase mutations and description of the clinical profile of 42 MODY-2 families. Diabetologia, 40: 217-224.
9. The Expert Committee on the Diagnosis and Classification of Diabetes Mellitus (1997). Report of the Expert Committee on the Diagnosis and Classification of Diabetes Mellitus. Diabetes Care, 20: 11831197.

10. Stone LM, Kahn SE, Fujimoto WY, Deeb SS \& Porte D (1996). A variation at position -30 of the beta-cell glucokinase gene promoter is associated with reduced betacell function in middle-aged J apaneseAmerican men. Diabetes, 45: 422-428.

11. Kramer CY (1956). Extension of multiple range tests to group means with unequal number of replications. Biometrics, 12: 309-310.

12. Matschinsky FM (1990). Glucokinase as glucose sensor and metabolic signal generator in pancreatic beta-cells and hepatocytes. Diabetes, 39: 647-652.

13. Hattersley AT, Clark PM, Page R, Levy J C, Cox L, Hales CN \& Tumer RC (1997). Glucokinase deficiency results in a betacell disorder characterized by normal fasting plasma proinsulin concentrations. Diabetologia, 40: 1367-1368. 